\title{
NOTAS SOBRE EL MARCO SOCIOECONOMICO DE LAS AUTONOMIAS
}

$353.072 .1: 330.1$

por

Ignacio Ballester RoS

SUMARIO: I. INTRODUCCION.- II. LA ESTRUCTURA ECONOMICA: 1. El SECTOR AGRARIO. 2. LA MINERIA Y LA INDUSTRIA. 3. EL COMERCIO Y OTROS SERVICIOS: A) El comercio. B) Otros servicios. 4. Los NIVELES DE RENTA MUNICIPAL Y EL PRODUCTO INTERIOR BRUTO.-III. EL EQUIPAMIENTO FAMILIAR EN EL AÑO 1975. IV. LOS INDICADORES SOCIOECONOMICOS.

\section{INTRODUCCION}

En el número anterior de esta REvista dE Estudios DE LA VIDA LOCAL se publicaron unas «Notas sobre el marco demográfico de las Autonomías", que constituían una crónica-comentario, basada en la información estadística contenida en el estudio titulado "Análisis socioeconómico de los Entes preautonómicos», publicado en el Anuario del Mercado Español, correspondiente al año 1980, que se edita bajo el patrocinio de Banesto.

En la referida crónica ya se indicaba que, dada la trascendencia e importancia de la información contenida en el mencionado estudio, se limitaba a las características demográficas de las Autonomías, dejando para un próximo número el examen de las características socioeconómicas. 
Damos por reproducida aquí la Introducción a la crónica ya citada, en cuanto en ella se hacía referencia al contenido de la información estadística que nos sirve de base al presente comentario.

\section{LA ESTRUCTURA ECONOMICA}

De forma somera se examinan los sectores económicos, destacando las características fundamentales de su estructura, dentro de las Autonomías, observando las diferencias cualitativas y cuantitativas que las distinguen.

\section{EL SECTOR AGRARIO}

Haremos referencia a la distribución de la tierra, a las explotaciones agrarias, al patrimonio agrario, a la producción final agraria y a la renta agraria, en cuanto a su distribución por Autonomías, expresada en porcentajes:

\begin{tabular}{|c|c|c|c|c|c|c|}
\hline & & $\begin{array}{l}\text { Distribución } \\
\text { de la tierra }\end{array}$ & $\begin{array}{c}\text { Explotaciones } \\
\text { agrarias }\end{array}$ & $\begin{array}{c}\text { Pattimonio } \\
\text { agrario }\end{array}$ & $\begin{array}{l}\text { Producción } \\
\text { final } \\
\text { agraria }\end{array}$ & $\begin{array}{l}\text { Renta } \\
\text { agraria }\end{array}$ \\
\hline Andalucía $\ldots \ldots \ldots \ldots$ & $\ldots$ & 17,3 & 16,4 & 17,2 & 19,4 & 23,7 \\
\hline Aragón $\ldots \ldots \ldots \ldots \ldots$ & & 9,4 & 5,0 & 7,0 & 7,0 & 6,5 \\
\hline $\begin{array}{lllll}\text { Asturias } & \ldots & \ldots & \ldots & \ldots\end{array}$ & $\ldots$ & 2,1 & 3,5 & 3,2 & 2,5 & 3,1 \\
\hline 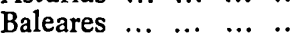 & $\ldots$ & 1,0 & 1,9 & 1,7 & 1,2 & 1,1 \\
\hline $\begin{array}{lllll}\text { Canarias } & \ldots & \ldots & \ldots & \ldots\end{array}$ & $\ldots$ & 1,5 & 4,0 & 2,4 & 2,5 & 2,3 \\
\hline Castilla-La Mancha .. & $\ldots$ & 15,7 & 8,8 & 10,9 & 8,7 & 8,6 \\
\hline Castilla y León ... .. & $\ldots$ & 20,7 & 15,3 & 16,7 & 15,7 & 15,1 \\
\hline $\begin{array}{lllll}\text { Cataluña } & \ldots & \ldots & \ldots & \ldots\end{array}$ & $\ldots$ & 6,3 & 5,7 & 8,9 & 11,4 & 7,2 \\
\hline Extremadura $\ldots . . . .$. & $\ldots$ & 8,2 & 5,2 & 4,9 & 4,4 & 4,6 \\
\hline $\begin{array}{ccccc}\text { Galicia } & \ldots & \ldots & \ldots & \ldots\end{array}$ & $\ldots$ & 5,8 & 15,1 & 10,7 & 7,6 & 8,8 \\
\hline Madrid $\ldots \ldots \ldots$ & $\ldots$ & 1,6 & 1,0 & 1,0 & 1,2 & 1,3 \\
\hline Murcia $\ldots \ldots \ldots \ldots$ & $\ldots$ & 2,2 & 3,0 & 3,4 & 3,3 & 3,5 \\
\hline $\begin{array}{lllll}\text { Navarra } & \ldots & \ldots & \ldots & \ldots\end{array}$ & $\ldots$ & 2,1 & 1,7 & 2,8 & 2,4 & 2,7 \\
\hline País Valenciano ... .. & $\ldots$ & 4,6 & 11,6 & 7,2 & 8,7 & 9,0 \\
\hline País Vasco... . . . . . .. & $\ldots$ & 1,5 & 1,8 & 2,0 & 2,0 & 2,5 \\
\hline
\end{tabular}

La distribución general de la tierra está en razón directa de la superficie de cada Autonomía. En 1977 las más extensas son, por este orden, Castilla y León, Andalucía y Castilla-La Mancha, que disponen, en conjunto, del 60 por 100 de las tierras de cultivo - una quinta parte del total cada una-. En prados y pastizales ocupa el primer lugar Castilla y León, con la quinta parte del total, seguida de Andalucía, Aragón, Extremadura y Castilla-La Mancha, con entre el 12 y el 13 por 100 cada una. Casti:a y León y Andalucía ocupan 
los dos primeros lugares por la superficie forestal, con el 16 por 100 cada una, seguidas de Andalucía y Castilla-La Mancha, con el 12 por 100 cada una.

La distribución de tierras de cultivo, prados y pastizales y superficie forestal se cifra, para el conjunto nacional, en el 41, el 14 y el 30 por 100 respectivamente, quedando un 15 por 100 de otras superficies. Por encima del promedio nacional de tierras de cultivo se sitúa una extensa zona, comprensiva de ambas Castillas y de Andalucía, y otra, más reducida, que abarca el País Valenciano, Murcia y Baleares. En prados y pastizales sobresalen Asturias, el País Vasco, Navarra y Aragón, Castilla y León, Madrid y Extremadura. En cuanto a la superficie forestal, ocupa el primer lugar Galicia, seguida de Asturias y el País Vasco, Cataluña, el País Valenciano y Baleares.

Las explotaciones agrarias -2.558.920, según el Censo Agrario de 1972 y de las que solamente 44.492 son sin tierras- se distribuyen de manera muy desigual entre las Autonomías. Sobresalen Andalucía, Castilla y León, y Galicia, con el 16, 15 y 11 por 100, respectivamente. Las explotaciones sin tierras, propias de las zonas ganaderas, destacan en ambas Castillas - comprendidas Madrid y Extremadura-, Andalucía y Navarra. Las explotaciones de hasta $10 \mathrm{hec}-$ táreas, que representan el 76 por 100 del total, sobresalen en Galicia y Asturias, Andalucía, País Valenciano, Murcia y Baleares, y en las islas Canarias. Las explotaciones de 11 a 100 hectáreas -20 por 100 del total- se sitúan preferentemente en el País Vasco, Navarra y Aragón, Cataluña y ambas Castillas -incluidas Extremadura y Madrid-. Las grandes explotaciones se extienden por gran parte del territorio peninsular, con preferencia en ambas Castillas, incluidas Madrid y Extremadura, Andalucía, Aragón, Cataluña y Navarra.

El patrimonio de la agricultura española, cifrado en 1972 en 4.878.512 millones de pesetas, se distribuye de manera predominante entre Andalucía (17 por 100), Castilla y León (16) y Castilla-La Mancha y Galicia con el 10. En tierras y plantaciones destacan Andalucía y ambas Castillas; en ganadería, Castilla y León, Galicia y Andalucía; en maquinaria, Andalucía, Galicia y Castilla y León, y en piscifactorías, ambas Castillas, Cataluña y Galicia. Las tierras y plantaciones representan el 82 por 100 del patrimonio, y por encima del promedio nacional se sitúan el País Valenciano y Murcia, Canarias, Baleares, Navarra, Castilla-La Mancha, Andalucía y Ara- 
gón, por este orden, mientras que en ganadería sobresalen Asturias, Extremadura y Madrid.

La producción final agraria se citró en 1976 en 906.597 millones de pesetas, figurando a la cabeza Andalucía, Castilla y León y Cataluña. El subsector agrícola representa el 52,66 por 100 de la producción agraria y en ellas resaltan Andalucía, ambas Castillas, el País Valenciano, Navarra y Canarias. En el subsector ganadero -42,01 por 100 - sobresalen Castilla y León, Cataluña y Galicia, aunque se extiende a otras Regiones este tipo de explotaciones. En el subsector forestal destacan Galicia, Andalucía y ambas Castillas; y en otras producciones, Andalucía, el País Valenciano, Galicia y Castilla y León.

La producción final agraria por persona agraria activa fue, en 1976, de 337.288 pesetas para el conjunto nacional, y por Autonomías se distribuye así:

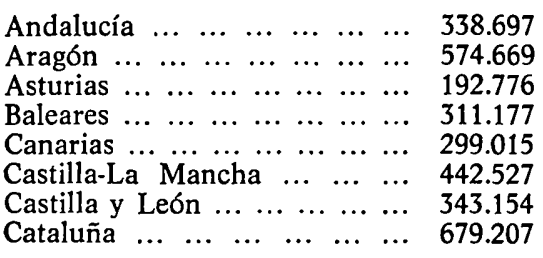

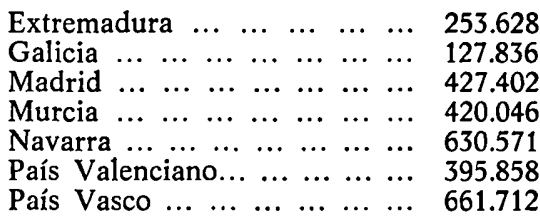

Como se observa, superan el promedio nacional diez Autonomías, pero entre ellas se sitúan en los primeros lugares, por este orden, Cataluña, el País Vasco, Navarra y Aragón. En segundo término figuran ambas Castillas -incluido Madrid-, Murcia, el País Valenciano y Andalucía.

La renta agraria fue en 1976 de 536.522 pesetas. Andalucía ocupa el primer lugar, seguida de Castilla y León; después se sitúan el País Valenciano, Galicia, Castilla-La Mancha, Cataluña y Aragón.

\section{LA MINERIA Y LA INDUSTRIA}

En la monografía que comentamos se presenta una información sobre producción vendible de las explotaciones mineras en 1977, distinguiendo cuatro grupos de productos. La producción energética se concentra básicamente en Asturias, con el 49 por 100 del total; y a ellas le siguen Castilla y León -el 25-, Cataluña -el 7- y aportaciones más reducidas de Galicia, Castilla-La Mancha y Andalucía. La producción de minerales metálicos se halla principalmente 
en Andalucía, con el 48 por 100, seguida por Castilla y León -15-, Murcia - 10—, País Vasco - 9-, Galicia -8- y pequeñas aportaciones de otras Autonomias. En cuanto a la producción de minerales no metálicos, más dispersa, ocupan los primeros lugares Cataluña y Navarra, con el 22 por 100 cada una; el País Valenciano y Asturias, con el 12 cada una; seguidas de Andalucía -8-, Castilla y León -7-, Galicia -6- y Castilla-La Mancha -5-. La producción de cantera procede de Castilla y León, con el 13 por $100, \mathrm{y}$ de Andalucía, Cataluña, Galicia y el País Vasco, con el 12 por 100 cada una.

En cuanto a la industria, presentamos la distribución, en porcentajes, por Autonomías, de los establecimientos industriales, el personal ocupado y el valor de la producción.

\begin{tabular}{|c|c|c|c|}
\hline & $\begin{array}{c}\text { Establecimientos } \\
\text { industriales } \\
\overline{1978}\end{array}$ & $\begin{array}{l}\text { Personal } \\
\text { ocupado } \\
\overline{1978}\end{array}$ & $\begin{array}{c}\text { Valor de la } \\
\text { producción } \\
\text { industrial } \\
\overrightarrow{1976}\end{array}$ \\
\hline 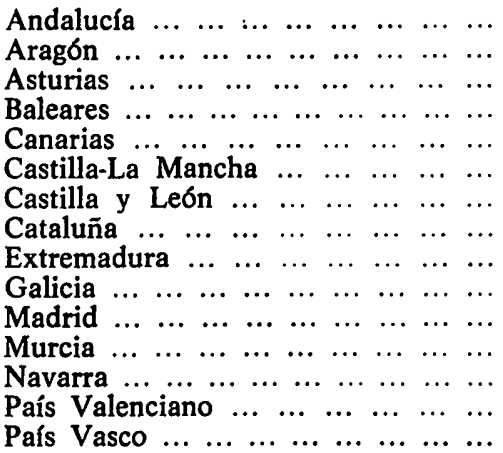 & $\begin{array}{r}11,5 \\
4,5 \\
2,6 \\
2,1 \\
1,8 \\
6,8 \\
11,6 \\
19,3 \\
3,1 \\
8,5 \\
6,9 \\
2,8 \\
1,9 \\
11,5 \\
5,1\end{array}$ & $\begin{array}{r}8,3 \\
3,7 \\
3,9 \\
1,1 \\
1,1 \\
3,2 \\
8,8 \\
24,8 \\
1,1 \\
4,9 \\
11,4 \\
2,2 \\
2,3 \\
11,9 \\
11,3\end{array}$ & $\begin{array}{r}10,7 \\
3,1 \\
8,6 \\
0,6 \\
1,6 \\
3,3 \\
7,5 \\
22,8 \\
0,6 \\
4,6 \\
9,2 \\
2,4 \\
2,1 \\
8,7 \\
14,2\end{array}$ \\
\hline
\end{tabular}

Los establecimientos industriales, 205.339 -no comprendidas las actividades de producción, transporte y distribución de energía eléctrica ni la de construcción de edificios y obras públicas-, según el Censo elaborado en 1978 por el Instituto Nacional de Estadística, se distribuyen de desigual forma entre las Autonomías, situándose en primer lugar Cataluña, con la quinta parte del total, seguida de Castilla y León, Andalucía y el País Valenciano, con el 12 por 100 cada una. El personal ocupado no presenta una distribución paralela a la de los establecimientos; si bien Cataluña sigue ocupando el primer lugar, con la cuarta parte de la población activa industrial, 
le siguen en importancia el País Valenciano, Madrid y el País Vasco, con el 12 por 100 cada una.

La producción industrial tenía en 1976 un valor de 4,4 billones de pesetas, ocupando también el primer lugar Cataluña, seguida del País Vasco y de Andalucía, Madrid, el País Valenciano, Asturias y Castilla y León. Si examinamos esta distribución por ramas de actividad industrial y Autonomías, observamos que en la explotación de minas y canteras destacan Andalucía, con el 17 por 100 del valor de producción, seguida del País Vasco, Cataluña y Murcia, con el 12 por 100 cada una; en las industrias de alimentación resalta $\mathrm{Ca}$ taluña, en primer término, con el 19 por 100, seguida de Andalucía y Castilla y León, con el 17; en bebidas y tabacos sobresalen Andalucía -24-, Cataluña -19- y Madrid -12-; en textiles, Cataluña, con el 71 por 100 del valor, seguida del País Valenciano, con el 13; en madera y corcho destacan igualmente el País Valenciano, con el 22, y Cataluña, con el 19 por 100; en papel y artes gráficas también ocupa el primer lugar Cataluña -30-, seguida del País Vasco -16- y Madrid -12-; en químicas ocupa también el primer lugar Cataluña -33-, seguida de Andalucía -16-, Madrid -12y el País Vasco - 10-; en vidrio, cerámica, cemento y material de construcción resaltan Cataluña -22-, el País Valenciano -18- y Andalucía -13-; en metálicas básicas sobresalen Asturias, con el 37 por 100, y el País Vasco, con el 30, y en transformados metálicos, Cataluña -27-, el País Vasco - 19- y Madrid -17-.

La distribución, dentro de cada Autonomía, del valor de la producción industrial, por ramas, en el año 1976, es la siguiente, expresada en porcentajes:

\begin{tabular}{|c|c|c|c|c|c|c|c|}
\hline & $\begin{array}{c}\text { Minas } \\
y \\
\text { canteras }\end{array}$ & $\begin{array}{l}\text { Alimen- } \\
\text { tación }\end{array}$ & $\begin{array}{c}\text { Bebidas } \\
y \\
\text { tabacos }\end{array}$ & $\begin{array}{l}\text { Texti- } \\
\text { les }\end{array}$ & $\begin{array}{l}\text { Calzado, } \\
\text { confec- } \\
\text { ción } \\
\text { y cueros }\end{array}$ & $\begin{array}{l}\text { Madera } \\
\text { y corcho }\end{array}$ & $\begin{array}{l}\text { Papel } \\
\text { y Artes } \\
\text { Gráficas }\end{array}$ \\
\hline Andalucía & 15,9 & 16,9 & 5,5 & 1,8 & 2,6 & 1,7 & 3,5 \\
\hline $\begin{array}{llllll} & \ldots & \ldots & \ldots & \ldots & \ldots \\
\end{array}$ & 2,7 & 18,6 & 1,3 & 1,9 & 8,7 & 3,5 & 8,6 \\
\hline $\begin{array}{llllll}\text { Asturias } & \ldots & \ldots & \ldots & \ldots & \ldots\end{array}$ & 10,2 & 3,5 & 0,6 & 0,1 & 0,5 & 0,5 & 1,0 \\
\hline $\begin{array}{llllll}\text { Baleares } & \ldots & \ldots & \ldots & \ldots & \ldots\end{array}$ & 1,3 & 19,9 & 4,4 & 1,7 & 41,1 & 7,3 & 3,6 \\
\hline $\begin{array}{cccccc}\text { Canarias } & \ldots & \ldots & \ldots & \ldots & \ldots \\
\end{array}$ & 56,3 & 11,0 & 13,4 & - & 0,4 & 1,9 & 6,7 \\
\hline Castilla-La Mancha... .. & 28,6 & 15,5 & 4,2 & 0,5 & 7,8 & 3,7 & 0,8 \\
\hline Castilla y León ......... . & 4,5 & 24,7 & 2,0 & 2,3 & 3,4 & 3,7 & 4,1 \\
\hline $\begin{array}{llllll}\text { Cataluña } & \ldots & \ldots & \ldots & \ldots & \end{array}$ & 5,4 & 9,0 & 2,1 & 14,3 & 5,3 & 2,5 & 6,1 \\
\hline Extremadura $\ldots \ldots \ldots \ldots$ & 1,6 & 53,8 & 3,8 & 2,9 & 2,5 & 5,5 & 1,5 \\
\hline $\begin{array}{cccccc}G & & & & & \end{array}$ & 15,4 & 17,2 & 2,3 & 1,1 & 3,9 & 6,0 & 2,8 \\
\hline Madrid ... ... & 0,3 & 7,8 & 3,2 & 0,8 & 8,0 & 2,6 & 6,4 \\
\hline $\begin{array}{llllll}\text { Murcia } & \ldots & \ldots & \ldots & \ldots & \ldots\end{array}$ & 50,1 & 11,8 & 1,7 & 0,8 & 3,5 & 2,4 & 0,9 \\
\hline 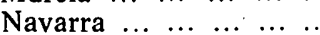 & 3,1 & 18,4 & 0,7 & 2,2 & 3,6 & 4,2 & 12,6 \\
\hline País Valenciano... $\ldots \ldots$ & 7,2 & 8,3 & 2,7 & 6,7 & 19,6 & 7,2 & 4,4 \\
\hline 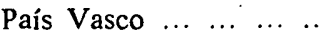 & 8,8 & 2,6 & 0,7 & 0,7 & 0,7 & 1,7 & 5,4 \\
\hline
\end{tabular}




\begin{tabular}{|c|c|c|c|c|}
\hline. & Químicas & $\begin{array}{l}\text { Vidrio, } \\
\text { cerámica, } \\
\text { cemento } \\
\text { y material } \\
\text { de construc- } \\
\text { ción }\end{array}$ & $\begin{array}{l}\text { Metálicas } \\
\text { básicas }\end{array}$ & $\begin{array}{l}\text { Transfor- } \\
\text { mados } \\
\text { metálicos }\end{array}$ \\
\hline 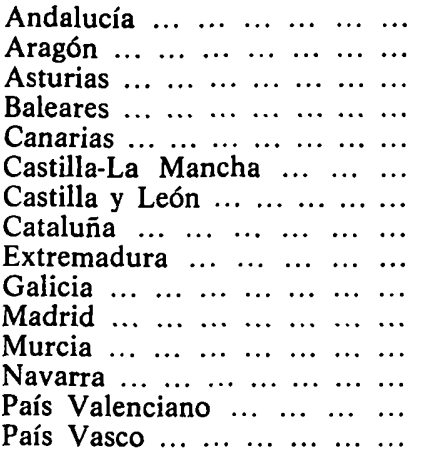 & $\begin{array}{r}21,8 \\
14,5 \\
2,3 \\
2,4 \\
3,4 \\
19,7 \\
18,0 \\
21,0 \\
14,7 \\
5,5 \\
18,8 \\
16,8 \\
8,1 \\
8,9 \\
10,4\end{array}$ & $\begin{array}{r}5,9 \\
5,1 \\
2,5 \\
11,1 \\
4,2 \\
11,4 \\
4,5 \\
4,7 \\
4,6 \\
4,3 \\
4,9 \\
2,9 \\
4,8 \\
9,9 \\
2,2\end{array}$ & $\begin{array}{r}10,4 \\
8,6 \\
75,4 \\
0,2 \\
0,1 \\
0,6 \\
9,6 \\
3,5 \\
8,6 \\
8,2 \\
14,2 \\
12,9 \\
37,7\end{array}$ & $\begin{array}{r}14,0 \\
26,5 \\
3,4 \\
7,0 \\
2,6 \\
7,2 \\
23,2 \\
26,0 \\
9,1 \\
33,0 \\
39,0 \\
9,1 \\
28,1 \\
11,6 \\
29,1\end{array}$ \\
\hline
\end{tabular}

Andalucía destaca por su producción en industrias químicas, de la alimentación, minas y canteras, transformados metálicos e industrias metálicas básicas. Aragón sobresale por los transformados metálicos, alimentación y químicas; Asturias, por las industrias metálicas básicas y las minas y canteras; Baleares, por el calzado, la alimentación y el vidrio y cerámica; Canarias, por minas y canteras y alimentación; Castilla-La Mancha, por minas y canteras, químicas, alimentación y vidrio y cerámica; Castilla y León, por los transformados metálicos, la alimentación y químicas; Cataluña, por los transformados metálicos, químicas y textiles; Extremadura, por la alimentación y químicas; Galicia, por transformados metálicos, alimentación y minas y canteras; Madrid, por transformados metálicos y químicas; Murcia, por minas y canteras, químicas y alimentación; Navarra, por transformados metálicos, metálicas básicas, alimentación y papel y artes gráficas; el País Valenciano, por el calzado, confección y cueros, metálicas básicas y transformados metálicos, y finalmente, el País Vasco, por las industrias metálicas básicas, los transformados metálicos y químicas.

\section{El COMERCIO Y OTROS SERVICIOS}

\section{A) El comercio}

El comercio constituye una de las principales actividades del sector de servicios. Pone a disposición de los consumidores flujos 
crecientes de bienes y servicios, atendiendo a la oportunidad del momento, la adecuación del lugar y el ofrecimiento a un precio que permita el equilibrio entre oferentes y demandantes. Su importancia económica y social es grande y ha de responder a los cambios operados en la sociedad, buscando cada día aumentos constantes de productividad. Frente al comercio mayorista y minorista tradicional se han creado nuevos puestos de comercio en mercados y galerías de alimentación; se ha introducido la técnica del libre servicio, en forma de autoservicios, superservicios y supermercados, así como establecimientos de gran superficie-almacenes populares, grandes almacenes e hipermercados-.

Para su mejor conocimiento se ha elaborado la siguiente tabla de cifras relativas, que permiten conocer la vitalidad de la acción comercial en el país:

\begin{tabular}{|c|c|c|c|c|}
\hline & $\begin{array}{c}\text { Licencias } \\
\text { comerciales } \\
\text { por mil } \\
\text { habitantes } \\
\overline{1978}\end{array}$ & $\begin{array}{c}\text { Puestos } \\
\text { por } 10.000 \\
\text { habitantes } \\
\text { en mercados } \\
\text { y galerías de } \\
\text { alimentación } \\
\overline{1977}\end{array}$ & $\begin{array}{c}\text { Superficie } \\
\text { de ventas } \\
\text { del comercio } \\
\text { minorista } \\
\text { en régimen } \\
\text { de libre } \\
\text { servicio } \\
M^{2} \text { por } 100 \\
\text { habitantes } \\
\overline{1977}\end{array}$ & $\begin{array}{c}\text { Establecimientos } \\
\text { de gran } \\
\text { superficie } \\
\text { Habitantes por } \\
\text { establecimiento } \\
\overline{1977}\end{array}$ \\
\hline $\begin{array}{llllll}\text { Andalucía } & \ldots & \ldots & \ldots & \ldots \\
\text { Aragón } & \ldots & \ldots & \ldots & \ldots & \ldots \\
\text { Asturias } & \ldots & \ldots & \ldots & \ldots & \ldots \\
\text { Baleares } & \ldots & \ldots & \ldots & \ldots & \ldots \\
\text { Canarias } & \ldots & \ldots & \ldots & \ldots & \ldots \\
\text { Castilla-La } & \text { Manch } & \ldots & \ldots & \ldots \\
\text { Castilla } & \text { y } & \text { León } & \ldots & \ldots & \ldots \\
\text { Cataluña } & \ldots & \ldots & \ldots & \ldots & \ldots \\
\text { Extremadura. } & \ldots & \ldots & \ldots & \ldots \\
\text { Galicia } & \ldots & \ldots & \ldots & \ldots & \ldots \\
\text { Madrid } & \ldots & \ldots & \ldots & \ldots & \ldots \\
\text { Murcia } & \ldots & \ldots & \ldots & \ldots & \ldots \\
\text { Navarra } & \ldots & \ldots & \ldots & \ldots & \ldots \\
\text { País Valenciano } & \ldots & \ldots & \ldots \\
\text { País } & \text { Vasco } & \ldots & \ldots & \ldots & \ldots \\
\text { Pasco } & \ldots & \ldots & \ldots\end{array}$ & $\begin{array}{l}18,8 \\
24,2 \\
21,5 \\
25,6 \\
22,0 \\
20,0 \\
21,0 \\
26,4 \\
20,9 \\
17,7 \\
21,2 \\
17,8 \\
20,4 \\
21,8 \\
21,6\end{array}$ & $\begin{array}{l}28 \\
25 \\
15 \\
24 \\
11 \\
20 \\
10 \\
36 \\
15 \\
26 \\
35 \\
16 \\
12 \\
32 \\
18\end{array}$ & $\begin{array}{l}3,0 \\
3,5 \\
2,8 \\
6,4 \\
4,0 \\
2,5 \\
3,2 \\
4,2 \\
1,8 \\
2,0 \\
3,2 \\
2,0 \\
3,0 \\
5,6 \\
4,4\end{array}$ & $\begin{array}{r}147,1 \\
168,6 \\
159,3 \\
164,2 \\
209,8 \\
323,6 \\
250,0 \\
208,3 \\
521,5 \\
246,8 \\
85,6 \\
224,9 \\
244,6 \\
135,3 \\
213,3\end{array}$ \\
\hline
\end{tabular}

En 1978 existían en el país 110.954 licencias de mayoristas y 689.488 de minoristas. El promedio nacional es de 22 licencias por mil habitantes. La distribución por Autonomías no ofrece una gran dispersión de valores, si bien sobresalen Cataluña, Baleares y Aragón, mientras que las mínimas en cuanto al número de licencias lo ostentan Galicia, Murcia y Andalucía. 
Igualmente, el número promedio de puestos en mercados y galerías de alimentación es de 26 por 10.000 habitantes. En este caso, la dispersión es más acentuada. Superan el promedio nacional Cataluña, Madrid y el País Valenciano, seguidas de Andalucía. Igualan o se aproximan al promedio nacional Galicia, Aragón y Baleares.

En 1977 existían 7.413 autoservicios, 2.086 superservicios y 536 supermercados de comercio minorista en régimen de libre servicio. La superficie de ventas, expresada en metros cuadrados por 100 habitantes, es de 3,5 para el conjunto nacional. Baleares, el País Valenciano, el País Vasco, Cataluña y Canarias ocupan, por este orden, los primeros lugares, seguidos de Aragón, con el mismo valor que el nacional.

En cuanto a establecimientos de gran superficie, existían en 1977 139 almacenes populares, 59 grandes almacenes y 22 supermercados. El promedio nacional de habitantes por establecimiento es de 168.112. Por debajo de este promedio-que indica disponibilidad mayor de esta clase de establecimientos-están Madrid, el País Valenciano, Andalucía, Asturias y Baleares.

\section{B) Otros servicios}

El sector terciario de la actividad económica tiene gran importancia, por el volumen de la población activa que emplea, la cuantía de las inversiones que a él se aplican y el Producto Interior Bruto que genera.

En el trabajo que comentamos se han analizado, como servicios básicos, la Enseñanza, la Sanidad, la Vivienda, la Hostelería y el Turismo, la red de carreteras y el parque de vehículos, los Bancos y Cajas de Ahorro y los espectáculos. Vamos a examinarlos sucintamente, presentando los valores relativos obtenidos, para mejor comparar el grado de desarrollo de cada una de las Autonomías.

La Enseñanza es evidentemente una de las ramas de actividad del sector de servicios de mayor importancia, debido a la creciente demanda de educación a todos los niveles y a los esfuerzos por extenderla, en términos cualitativos y cuantitativos, a todos los miembros de la sociedad, por justa exigencia social y porque constituye una necesidad básica si se quieren alcanzar niveles adecuados de desarrollo económico.

El alumnado del curso 1977-1978 se distribuye por niveles y cla- 
ses de estudio y por Autonomías, en términos relativos, en esta forma:

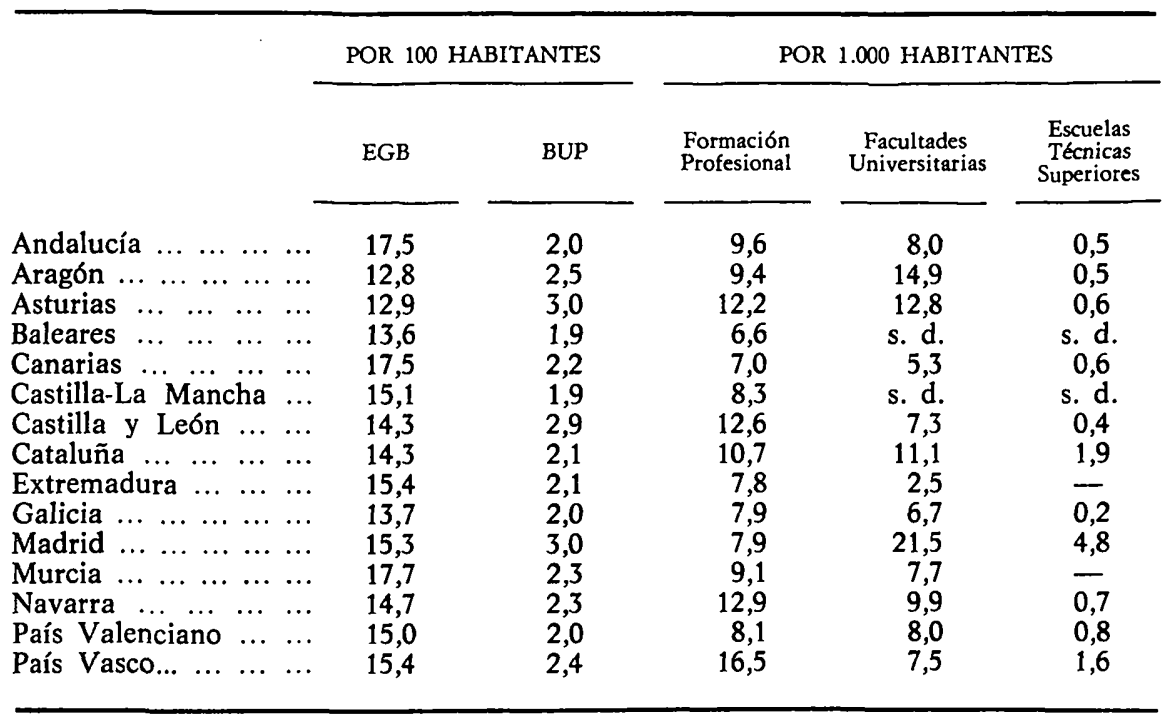

En el conjunto nacional, estudian EGB y BUP el 15,2 y el 2,3 por 100 habitantes, respectivamente, y Formación Profesional, Facultades Universitarias o Escuelas Técnicas Superiores, el 9,8, 9,5 y 1,2 por 1.000 habitantes, respectivamente.

La dispersión de valores por Autonomías no es grande en EGB y BUP. Murcia, Andalucía y Canarias destacan por sus tasas, más altas que la nacional, junto con Extremadura, el País Vasco y Madrid, mientras que, por contraste, las mínimas corresponden a Aragón y Asturias; pero ello puede resultar engañoso, pues hay que tener en cuenta también el alumnado de BUP. En cuanto a éste, destacan precisamente Asturias y Aragón y Castilla y León, juntamente con Madrid, Murcia, Navarra y el País Vasco. En conjunto, sobresalen por el alumnado de ambos niveles Andalucía, Canarias, Madrid, Murcia y el País Vasco, y, aunque la dispersión es muy pequeña, las tasas menores corresponden a Galicia, Aragón y Baleares.

La dispersión es, por el contrario, muy acentuada cuando se trata de los estudios de formación profesional y de los universitarios. En Formación Profesional destaca el alumnado del País Vasco y Navarra, Asturias y Castilla y León y Cataluña. En los estudios de 
Facultades Universitarias sobresalen Madrid, por encima de todas, y a continuación Aragón, Asturias, Cataluña y Navarra. En cuanto a las Escuelas Técnicas Superiores, resaltan, a su vez, Madrid, el País Vasco y Cataluña. Parece deducirse que la distribución del alumnado universitario y de escuelas técnicas obedece más a la ubicación de los centros que a la naturaleza de los alumnos.

La Sanidad es un claro exponente del grado de evolución de la sociedad y se manifiesta por el equipo sanitario disponible, incluidas las instalaciones técnicas como el elemento humano.

En la tabla siguiente se presenta información relativa al número de profesionales y de unidades de hospitalización, por mil habitantes, en el año 1977.

\begin{tabular}{|c|c|c|c|c|c|c|}
\hline & Médicos & $\begin{array}{l}\text { Veterina- } \\
\text { rios }\end{array}$ & $\begin{array}{c}\text { Farma- } \\
\text { céuticos }\end{array}$ & $\begin{array}{l}\text { Odontó. } \\
\text { logos y } \\
\text { estoma- } \\
\text { tólogos }\end{array}$ & $\begin{array}{l}\text { Asistentes } \\
\text { técnicos } \\
\text { sanitarios }\end{array}$ & $\begin{array}{l}\text { Unidades } \\
\text { de hospi- } \\
\text { talización }\end{array}$ \\
\hline Andalucía $\ldots \ldots \ldots \ldots$ & 1,6 & 0,2 & 0,5 & 0,6 & 2,1 & 4,6 \\
\hline Aragón $\ldots \ldots \ldots \ldots \ldots$ & 2,4 & 0,4 & 0,5 & 1,2 & 1,6 & 7,2 \\
\hline $\begin{array}{lllll}\text { Asturias } & \ldots & \ldots & \ldots & \ldots\end{array}$ & 1,6 & 0,2 & 0,4 & 1,3 & 1,8 & 5,0 \\
\hline Baleares $\ldots \ldots \ldots \ldots \ldots$ & 1,6 & 0,2 & 0,6 & 1,4 & 1,9 & 6,2 \\
\hline $\begin{array}{lllll}\text { Canarias } & \ldots & \ldots & \ldots & \ldots\end{array}$ & 1,2 & 0,1 & 0,3 & 0,7 & 1,1 & 4,8 \\
\hline Castilla-La Mancha ... & 1,3 & 0,4 & 0,5 & 0,6 & 1,6 & 4,4 \\
\hline Castilla y León $\ldots \ldots$ & 2,0 & 0,5 & 0,5 & 1,0 & 2,1 & 6,0 \\
\hline $\begin{array}{ccccc}\text { Cataluña } & \ldots & \ldots & \ldots & \ldots\end{array}$ & 2,1 & 0,1 & 0,6 & 1,0 & 2,2 & 5,6 \\
\hline Extremadura $\ldots \ldots \ldots$ & 1,2 & 0,4 & 0,5 & 0,6 & 1,6 & 4,1 \\
\hline $\begin{array}{cccccc}\text { Galicia } & \ldots & \ldots & \ldots & \ldots & \ldots\end{array}$ & 1,4 & 0,2 & 0,5 & 1,0 & 1,5 & 4,1 \\
\hline 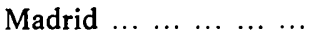 & 2,9 & 0,2 & 0,8 & 2,0 & 3,7 & 6,3 \\
\hline $\begin{array}{llllll}\text { Murcia } & \ldots & \ldots & \ldots & \ldots & \ldots\end{array}$ & 1,7 & 0,1 & 0,5 & 0,7 & 2,3 & 4,4 \\
\hline $\begin{array}{lllll}\text { Navarra } & \ldots & \ldots & \ldots & \ldots\end{array}$ & 2,2 & 0,3 & 0,6 & 1,1 & 3,1 & 8,5 \\
\hline País Valenciano ... ... & 1,9 & 0,1 & 0,5 & 1,1 & 2,6 & 4,6 \\
\hline País Vasco... . . . . . . . & 1,8 & 0,1 & 0,4 & 1,1 & 1,5 & 6,5 \\
\hline
\end{tabular}

Las Autonomías mejor dotadas de médicos son Madrid, Aragón y Navarra, Cataluña y Castilla y León, que superan el promedio nacional de 1,9 médicos por mil habitantes. Por el contrario, las mejor dotadas de veterinarios son las predominantemente agrarias, como en especial ambas Castillas, Extremadura, Aragón y Navarra; aparecen deficitarias Canarias, Cataluña, Murcia, el País Valenciano y el País Vasco. Son Madrid, Navarra, Cataluña y Baleares las Autonomías mejor servidas de farmacéuticos, si bien la dispersión de valores es muy reducida, apareciendo deficitarias Asturias, el País Vasco y Canarias. En cuanto a los odontólogos y estomatólogos, la dis- 
persión de valores es mayor y se presentan como deficitarias Andalucía, Extremadura y Murcia, Baleares y Canarias. Con referencia a los asistentes técnicos sanitarios, las mejor dotadas son Madrid, Navarra, el País Valenciano y Murcia, así como Cataluña, Castilla y León y Andalucía.

En el conjunto español se dispone de 5,3 unidades de hospitalización -camas- por mil habitantes. Las Autonomías mejor dotadas son Navarra, Aragón, el País Vasco, Madrid, Cataluña y Baleares y, finalmente, Castilla y León; las más deficitarias son Extremadura y Galicia.

La construcción de viviendas en el período 1974-1977 se elevó a 1,4 millones, con un promedio anual de 344.250. La proporción de viviendas protegidas y libres es muy similar en el conjunto nacional, no así entre las Autonomías. Los puntos extremos son Baleares, con el 17,1 y el 82,9 de viviendas construidas protegidas y libres respectivamente, frente a Extremadura, con el 97,4 y el 2,6, respectivamente. El total de viviendas construidas se distribuye muy desigualmente, ya que son Cataluña, Madrid, Andalucía y el País Valenciano las que presentan mayores porcentajes, absorbiendo las dos terceras partes del total.

El turismo tiene una importancia económica de primer orden, en especial en las zonas de mayores niveles de receptividad, que, en gran parte, depende, a su vez, del número y capacidad de las instalaciones hoteleras, que constituyen la oferta de alojamientos. Los índices de capacidad hotelera - número de plazas por cien, dividido por el producto: población y superficie- permiten determinar el distinto peso relativo de las Autonomías en orden a la oferta hotelera. Ocupa, con mucho, el primer lugar Baleares, con un índice de 6,84, y le sigue Canarias, con un 0,59; Madrid, con el 0,13, y Navarra, con el 0,10 . Con valores de 0,9 se sitúan Cataluña, el País Vasco y el País Valenciano, seguidas de Murcia, con el 0,8. Las restantes presentan valores inferiores.

La longitud de las carreteras y el parque automóvil, informaciones básicas para el estudio del transporte, se presentan en términos relativos en la siguiente tabla: 


\begin{tabular}{|c|c|c|c|c|c|c|}
\hline & & \multirow[b]{2}{*}{$\begin{array}{c}\text { Carreteras } \\
\text { kms. por } \mathrm{km}^{2}\end{array}$} & \multicolumn{2}{|c|}{ POR 100 HABITANTES } & \multicolumn{2}{|c|}{ POR 1.000 HABITANTES } \\
\hline & & & Turismos & Camiones & Autobuses & $\begin{array}{c}\text { Tractores } \\
\text { industriales }\end{array}$ \\
\hline 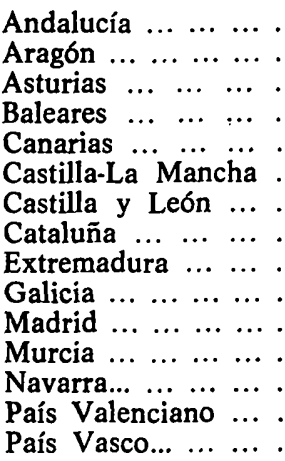 & $\begin{array}{l}\cdots \\
\cdots \\
\cdots \\
\cdots \\
\cdots \\
\cdots \\
\cdots \\
\cdots \\
\cdots \\
\cdots \\
\cdots \\
\cdots \\
\cdots \\
\cdots\end{array}$ & $\begin{array}{l}0,26 \\
0,20 \\
0,46 \\
0,42 \\
0,95 \\
0,22 \\
0,30 \\
0,34 \\
0,20 \\
0,47 \\
0,39 \\
0,29 \\
0,33 \\
0,35 \\
0,54\end{array}$ & $\begin{array}{r}11,5 \\
15,3 \\
17,2 \\
27,5 \\
15,5 \\
10,5 \\
15,1 \\
24,3 \\
9,2 \\
13,1 \\
25,8 \\
12,3 \\
19,6 \\
17,8 \\
18,7\end{array}$ & $\begin{array}{l}2,6 \\
3,4 \\
2,8 \\
3,6 \\
3,8 \\
3,5 \\
3,3 \\
3,9 \\
2,3 \\
2,5 \\
3,1 \\
3,4 \\
4,8 \\
3,4 \\
3,0\end{array}$ & $\begin{array}{l}0,9 \\
1,1 \\
1,4 \\
2,5 \\
2,0 \\
0,8 \\
0,9 \\
1,0 \\
0,6 \\
1,7 \\
0,9 \\
0,9 \\
1,6 \\
0,7 \\
1,1\end{array}$ & $\begin{array}{r}2,4 \\
12,1 \\
6,6 \\
1,2 \\
3,5 \\
4,1 \\
6,4 \\
7,6 \\
2,5 \\
2,8 \\
3,4 \\
8,7 \\
26,6 \\
7,3 \\
6,2\end{array}$ \\
\hline
\end{tabular}

El promedio nacional de longitud de carreteras es de $0,30 \mathrm{kms}$. por $\mathrm{km}^{2}$. Los valores más altos corresponden, en líneas generales, a las Autonomías de menor superficie, y así ocupa el primer lugar Canarias, seguida del País Vasco, Galicia, Asturias, Baleares, Madrid, País Valenciano, Cataluña y Navarra.

Las disponibilidades de turismos es, para el conjunto nacional, de 17,6 por 100 habitantes. Las Autonomías mejor dotadas son Baleares y Cataluña, Madrid, Navarra y el País Vasco y el País Valenciano. La distribución de camiones presenta una dispersión pequeña entre las Autonomías; por encima del promedio nacional de 3,2 camiones por 100 habitantes se hallan situadas nueve Autonomías, ocupando el primer lugar Navarra; la menor disponibilidad corresponde a Extremadura. La tasa nacional de autobuses es de 1,1 por mil habitantes, y la de tractores industriales, de 5,4; los primeros predominan en seis Autonomías: Baleares y Canarias, Madrid y Navarra, Asturias, Aragón y País Vasco; y los segundos, en Navarra, que ocupa el primer lugar, seguida de Aragón, Murcia, Cataluña y País Valenciano, País Vasco y Asturias.

Existen en España, en 1978, 29,1 oficinas bancarias por cada cien mil habitantes; la distribución es, en líneas generales, muy homogénea, ya que diez Autonomías rebasan el promedio nacional de oficinas bancarias, ocupando los primeros lugares Baleares, Navarra y Cataluña; las Autonomías peor asistidas, en este servicio, son Canarias, Andalucía, ambas Castillas y Extremadura. El saldo 
medio de depósitos bancarios, en el conjunto nacional, es de 98.700 pesetas por habitante; con saldos medios superiores al nacional solamente figuran cinco Autonomías: Madrid, en primer lugar, seguida de Cataluña y el País Vasco, Navarra y el País Valenciano.

\section{LOS NIVELES DE RENTA MUNICIPAL y EL Producto INTERIor Bruto}

En el trabajo que comentamos se presenta una información amplia, referida a cada Autonomía, en la que se detallan por niveles de renta a todos los Municipios españoles, y se obtiene, como complemento, el nivel medio de renta "per capita», referido al año 1975. En consecuencia, los resultados nos llevan a considerar que este nivel medio es de 200.001 a 250.000 pesetas en Madrid y Baleares; de 150.001 a 200.000 en Cataluña, Navarra, País Vasco y Canarias; de 125.001 a 150.000 en el País Valenciano, Aragón y Asturias; de 100.001 a 125.000 en Andalucía, Murcia y ambas Castillas; e inferior a 100.000 en las demás Autonomías.

El Producto Interior Bruto, en 1977, se presenta, en porcentajes, por sectores económicos y Autonomías, en la siguiente tabla:

\begin{tabular}{|c|c|c|c|c|}
\hline & Agrario & Industrial & De servicios & En conjunto \\
\hline $\begin{array}{lllllll}\text { Andalucía } & \ldots & \ldots & \ldots & \ldots & \ldots & \ldots\end{array}$ & 21,6 & 10,9 & 12,6 & 12,5 \\
\hline $\begin{array}{llllllll}\text { Aragón } & \ldots & \ldots & \ldots & \ldots & \ldots & \ldots & \ldots\end{array}$ & 5,5 & 3,3 & 3,1 & 3,4 \\
\hline $\begin{array}{lllllll}\text { Asturias } & \ldots & \ldots & \ldots & \ldots & \ldots & \ldots\end{array}$ & 2,5 & 4,1 & 2,4 & 3,1 \\
\hline $\begin{array}{lllllll}\text { Baleares } & \ldots & \ldots & \ldots & \ldots & \ldots & \ldots\end{array}$ & 1,2 & 1,2 & 2,8 & 2,0 \\
\hline $\begin{array}{llllllll}\text { Canarias } & \ldots & \ldots & \ldots & \ldots & \ldots & \ldots & \ldots\end{array}$ & 2,8 & 1,7 & 4,0 & 3,0 \\
\hline $\begin{array}{lllll}\text { Castilla-La } & \ldots & \ldots & \ldots \\
\end{array}$ & 8,7 & 3,3 & 2,8 & 3,5 \\
\hline Castilla y León $\ldots . . . . . . . .$. & 15,6 & 7,6 & 7,5 & 8,2 \\
\hline $\begin{array}{lllllll}\text { Cataluña } & \ldots & \ldots & \ldots & \ldots & \ldots & \ldots\end{array}$ & 8,1 & 24,2 & 18,9 & 20,0 \\
\hline $\begin{array}{lllllll}\text { Extremadura } & \ldots & \ldots & \ldots & \ldots & \ldots\end{array}$ & 4,4 & 1,1 & 1,7 & 1,7 \\
\hline $\begin{array}{llllllll}\text { Galicia } & \ldots & \ldots & \ldots & \ldots & \ldots & \ldots & \ldots\end{array}$ & 10,9 & 5,1 & 5,5 & 5,8 \\
\hline $\begin{array}{llllllll}\text { Madrid } & \ldots & \ldots & \ldots & \ldots & \ldots & \ldots & \ldots\end{array}$ & 1,3 & 14,2 & 20,4 & 16,3 \\
\hline $\begin{array}{ccccccc}\operatorname{Murcia} & \ldots & \ldots & \ldots & \ldots & \ldots & \ldots\end{array}$ & 3,1 & 2,0 & 1,9 & 2,1 \\
\hline $\begin{array}{lllllll}\text { Navarra } & \ldots & \ldots & \ldots & \ldots & \ldots & \ldots\end{array}$ & 2,1 & 1,8 & 1,2 & 1,5 \\
\hline $\begin{array}{llllll}\text { País Valenciano } & \ldots & \ldots & \ldots & \ldots\end{array}$ & 9,0 & 9,7 & 9,3 & 9,4 \\
\hline 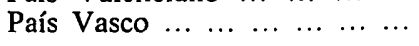 & 3,2 & 10,8 & 5,9 & 7,5 \\
\hline $\begin{array}{lllllll}\text { TOtAL } & \ldots & \ldots & \ldots & \ldots & \ldots\end{array}$ & 100 & 100 & 100 & 100 \\
\hline $\begin{array}{llllllll}\text { Andalucía } & \ldots & \ldots & \ldots & \ldots & \ldots & \ldots\end{array}$ & 15,3 & 31,2 & 53,5 & 100 \\
\hline $\begin{array}{llllllll}\text { Aragón } & \ldots & \ldots & \ldots & \ldots & \ldots & \ldots & \ldots\end{array}$ & 14,5 & 37,2 & 48,3 & 100 \\
\hline $\begin{array}{lllllllll}\text { Asturias } & \ldots & \ldots & \ldots & \ldots & \ldots & \ldots & \ldots\end{array}$ & 7,2 & 50,9 & 41,9 & 100 \\
\hline $\begin{array}{lllllll}\text { Baleares } & \ldots & \ldots & \ldots & \ldots & \ldots & \ldots\end{array}$ & 5,2 & 22,5 & 72,3 & 100 \\
\hline $\begin{array}{llllllll}\text { Canarias } & \ldots & \ldots & \ldots & \ldots & \ldots & \ldots & \ldots\end{array}$ & 8,3 & 21,2 & 70,5 & 100 \\
\hline $\begin{array}{llllll}\text { Castilla-La } & \text { Mancha } & \ldots & \ldots & \ldots\end{array}$ & 21,8 & 35,9 & 42,3 & 100 \\
\hline Castilla y León $\ldots \ldots \ldots \ldots$ & 16,9 & 35,0 & 48,1 & 100 \\
\hline
\end{tabular}




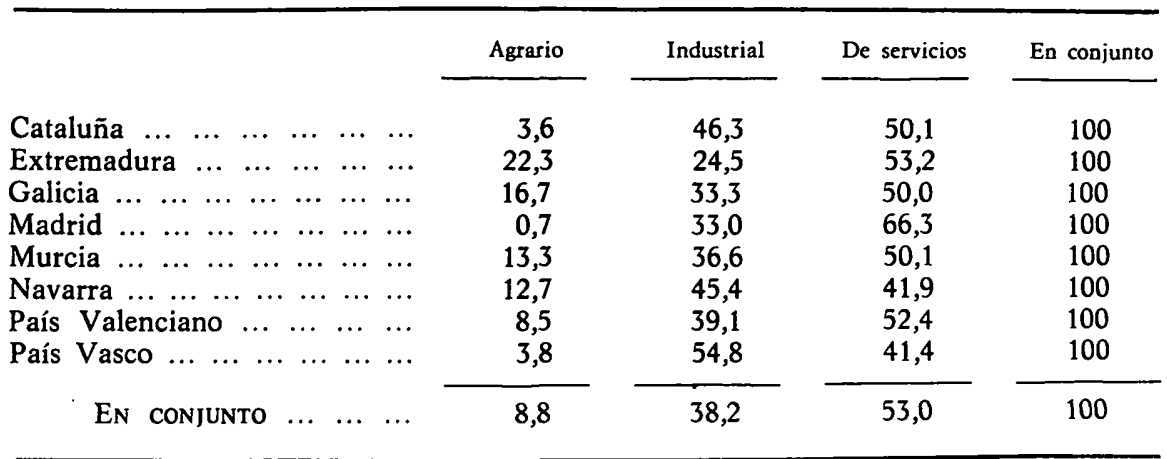

La distribución del Producto Interior Bruto por Autonomías denota el peso desigual de cada una de ellas, en el conjunto de la actividad económica nacional. Como se observa, el primer lugar lo ocupa Cataluña, con la quinta parte del PIB, seguida de Madrid, con el 16, Andalucía (12), País Valenciano (9), Castilla y León (8) y País Vasco $(7,5)$. En conjunto, estas seis Autonomías representan el 74 por 100 del PIB. La distribución en el sector industrial es muy similar, si bien el País Vasco supera al País Valenciano y a Castilla y León. También se asemeja mucho la distribución del sector de servicios, si bien en éste Madrid supera a Barcelona. Difiere, sin embargo, la distribución en el sector agrario, ya que, por orden de importancia, ocupan los primeros lugares Andalucía, Castilla y León, Galicia, el País Valenciano, Castilla-La Mancha y Cataluña.

Las consideraciones anteriores hacen referencia a cada sector independientemente examinado. En la segunda parte de la tabla se presenta el peso de cada sector dentro de cada una de las Autonomías y también en el conjunto nacional. En este último, el sector agrario representa sólo el 9 por 100 del PIB; el industrial, el 38, y el de servicios, el 53. En todas las Autonomías el sector agrario tiene un peso menor que el industrial y el de servicios, aunque en Extremadura el PIB del sector agrario se acerca en valor al del sector industrial. En determinadas Autonomías -Asturias, Navarra y el País Vasco-, el PIB del sector industrial es superior al de los servicios. En las restantes es predominante el PIB del sector de servicios.

Superan el PIB nacional del sector agrario -8,8- ocho Autonomías, que configuran una gran zona, muy extensa, que comprende 
Galicia, ambas Castillas y Extremadura, Andalucía y Murcia, Navarra y Aragón. El PIB nacional del sector industrial sólo es superado por cinco Autonomías: Asturias, País Vasco, Navarra, Cataluña y País Valenciano, que podemos considerar como grandes focos industriales. En cuanto al sector de servicios, superan el PIB nacional -53- otras cinco Autonomías: Madrid, Extremadura, Andalucía, Canarias y Baleares, grandes centros de la actividad de servicios.

\section{EL EQUIPAMIENTO FAMILIAR EN EL AÑO 1975}

Tomando como base la Encuesta de Equipamiento y Nivel Cultural de las Familias, llevada a cabo por el Instituto Nacional de Estadística en el año 1975, se han obtenido los valores relativos, expresivos de la dotación de los hogares españoles en ciertos servicios básicos y del grado de posesión de determinados bienes estrechamente ligados al nivel de comodidad y confort.

Ciertamente existe una alta correlación entre el grado de desarrollo de las Autonomías y el nivel de dotación de bienes y servicios de los hogares, pues son precisamente las áreas geográficas con más elevado índice de industrialización y con mayor número de grandes centros urbanos los que aparecen mejor equipados.

A continuación se indican, en porcentajes, los grados de posesión de los bienes y servicios que se detallan, por Autonomías:

\begin{tabular}{|c|c|c|c|c|c|c|c|}
\hline & $\begin{array}{c}\text { Número } \\
\text { de } \\
\text { hogares }\end{array}$ & $\begin{array}{c}\text { Agua } \\
\text { corriente }\end{array}$ & $\begin{array}{l}\text { Servicios } \\
\text { de aseo } \\
\text { e higiene }\end{array}$ & $\begin{array}{c}\text { Calefac- } \\
\text { ción } \\
\text { central }\end{array}$ & $\begin{array}{l}\text { Calefac- } \\
\text { ción. } \\
\text { indivi- } \\
\text { dual }\end{array}$ & $\begin{array}{l}\text { Frigo- } \\
\text { rífico }\end{array}$ & $\begin{array}{l}\text { Lava- } \\
\text { dora } \\
\text { automá- } \\
\text { tica }\end{array}$ \\
\hline Andalucía $\ldots \ldots \ldots$ & 15,72 & 78,7 & 74,5 & 0,7 & 30,0 & 64,8 & 20,8 \\
\hline Aragón $\ldots \ldots \ldots \ldots \ldots \ldots$ & 3,57 & 92,1 & 85,6 & 11,5 & 46,6 & 79,6 & 27,8 \\
\hline $\begin{array}{llllll}\text { Asturias } & \ldots & \ldots & \ldots & \ldots & \ldots\end{array}$ & 3,19 & 87,8 & 83,0 & 6,7 & 36,8 & 56,2 & 35,8 \\
\hline $\begin{array}{llllll}\text { Baleares } & \ldots & \ldots & \ldots & \ldots & \ldots\end{array}$ & 1,77 & 66,6 & 83,8 & 1,7 & 56,0 & 90,9 & 23,8 \\
\hline $\begin{array}{llllll}\text { Canarias } & \ldots & \ldots & \ldots & \ldots & \ldots\end{array}$ & 2,94 & 88,9 & 87,4 & - & 1,4 & 53,4 & 22,1 \\
\hline Castilla-La Mancha ... ... & 4,68 & 75,8 & 58,3 & 3,7 & 36,8 & 61,4 & 13,7 \\
\hline Castilla y Leon ... .... ... & 9,57 & 79,6 & 67,0 & 5,7 & 35,6 & 57,4 & 21,9 \\
\hline 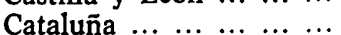 & 16,34 & 97,8 & 97,3 & 3,4 & 84,8 & 92,2 & 34,7 \\
\hline $\begin{array}{llllll} & \text { Extremadura } & \ldots & \ldots & \ldots & \ldots\end{array}$ & 3,10 & 61,2 & 50,6 & 1,0 & 6,3 & 48,9 & 12,0 \\
\hline $\begin{array}{cccccc}\text { Galicia } & \ldots & \ldots & \ldots & \ldots & \ldots\end{array}$ & 7,47 & 70,5 & 58,3 & 1,4 & 25,4 & 36,0 & 14,7 \\
\hline $\begin{array}{llllll} & \\
\text { Madrid } & \ldots & \ldots & \ldots & \ldots & \ldots \\
& \ldots & \ldots & \ldots & \ldots & \ldots\end{array}$ & 12,47 & 97,4 & 96,3 & 21,9 & 61,2 & 92,8 & 46,3 \\
\hline 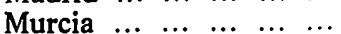 & 2,31 & 86,9 & 77,6 & 0,8 & 63,7 & 77,1 & 18,4 \\
\hline 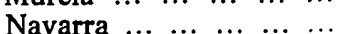 & 1,29 & 96,6 & 95,6 & 19,0 & 55,3 & 84,0 & 38,6 \\
\hline País Valenciano $\ldots . . . . . .$. & 9,98 & 93,0 & 94,4 & 1,1 & 63,7 & 87,4 & 26,1 \\
\hline País Vasco $\ldots \ldots \ldots$ & 5,60 & 98,6 & 98,2 & 6,5 & 50,6 & 86,7 & 41,0 \\
\hline
\end{tabular}




\begin{tabular}{|c|c|c|c|c|c|c|c|}
\hline & $\begin{array}{c}\text { Lavava- } \\
\text { jillas }\end{array}$ & $\begin{array}{c}\text { Aspira- } \\
\text { dora }\end{array}$ & TV & $\begin{array}{l}\text { Toca. } \\
\text { discos }\end{array}$ & $\begin{array}{l}\text { Magne- } \\
\text { tofono }\end{array}$ & $\begin{array}{l}\text { Cámara } \\
\text { fotográ- } \\
\text { fica }\end{array}$ & $\begin{array}{l}\text { Proyec- } \\
\text { tor y } \\
\text { toma- } \\
\text { vistas }\end{array}$ \\
\hline Andalucía... $\ldots \ldots \ldots \ldots$ & 1,5 & 2,5 & 77,5 & 13,9 & 11,7 & 12,1 & 1,5 \\
\hline Aragón $\ldots \ldots \ldots \ldots \ldots$ & 2,6 & 6,2 & 78,3 & 17,1 & 17,2 & 19,1 & 2,6 \\
\hline $\begin{array}{llllll}\text { Asturias } & \ldots & \ldots & \ldots & \ldots & \ldots\end{array}$ & 2,3 & 10,6 & 75,5 & 15,9 & 15,3 & 16,5 & 2,4 \\
\hline $\begin{array}{llllll}\text { Baleares } & \ldots & \ldots & \ldots & \ldots & \ldots\end{array}$ & 1,7 & 9,8 & 77,1 & 18,2 & 15,2 & 22,0 & 4.2 \\
\hline $\begin{array}{llllll}\text { Canarias } & \ldots & \ldots & \ldots & \ldots & \ldots\end{array}$ & 1,0 & 4,6 & 72,5 & 17,7 & 14,4 & 12,7 & 3.6 \\
\hline Castilla-La Mancha ... ... & 0,8 & 2,1 & 73,1 & 8,2 & 8,1 & 8,5 & 1,0 \\
\hline Castilla y Leon ... ....... & 1,6 & 6,7 & 70,0 & 12,5 & 11,8 & 13,4 & 1,4 \\
\hline 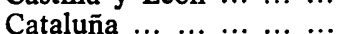 & 3,0 & 10.4 & 89,0 & 29.5 & 22,3 & 30,9 & 5,1 \\
\hline Extremadura $\ldots \ldots \ldots \ldots$ & 1,6 & 1,5 & 62,1 & 7,1 & 8,4 & 7,3 & 0,8 \\
\hline $\begin{array}{llllll}\text { Galicia } & \ldots & \ldots & \ldots & \ldots & \ldots\end{array}$ & 1,4 & 5,8 & 56,6 & 8,2 & 7,8 & 8,5 & 1,3 \\
\hline $\begin{array}{llllll}\text { Madrid } & \ldots & \ldots & \ldots & \ldots & \ldots\end{array}$ & 5,9 & 18,7 & 90,8 & 31,9 & 25,6 & 33,1 & 6,2 \\
\hline $\begin{array}{cccccc}\operatorname{Murcia} & \ldots & \ldots & \ldots & \ldots & \ldots\end{array}$ & 1,1 & 2,9 & 80,5 & 11,6 & 9,9 & 11,2 & 1,5 \\
\hline 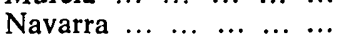 & 3,3 & 9,1 & 83,9 & 17,9 & 20,4 & 21,1 & 1,5 \\
\hline País Valenciano ........... & 2,8 & 6,2 & 84,3 & 18,9 & 17,0 & 22,4 & 3,1 \\
\hline País Vasco $\ldots \ldots \ldots \ldots$ & 4,0 & 25,6 & 89,6 & 23,5 & 23,0 & 26,4 & 3,1 \\
\hline
\end{tabular}

La distribución del número de hogares por Autonomías da idea de la concentración de la población en grandes urbes y en las zonas industriales. Cataluña, Andalucía, Madrid, el País Valenciano y Castilla y León aparecen como las más populosas, seguidas del País Vasco y Castilla-La Mancha.

Se dispone de agua corriente en el 86,8 por 100 de los hogares españoles. Una gran zona, con disponibilidades superiores al conjunto nacional, se configura con el País Vasco, Aragón y Navarra, Cataluña, el País Valenciano y Murcia. Separada de ella hemos de destacar, al mismo nivel, a Madrid, Asturias y Canarias. Las tasas más altas corresponden al País Vasco y Cataluña.

Muy parecida a la anterior es la disponibilidad de servicios de aseo e higiene, aunque con tasas un poco más bajas. El promedio nacional de hogares con este servicio es del 82,4 por 100 . La distribución es similar a la anterior, incorporando también a Baleares.

Las disponibilidades de calefacción en el conjunto nacional se cifran en el 5,6 por 100 de hogares con calefacción central y el 48,7 con calefacción individual. La dispersión de valores en las Autonomías es grande y depende de varios factores, entre los que figuran las condiciones climáticas. Madrid, Navarra y Aragón, el País Vasco, Castilla y León y Asturias, con clima duro o con excesiva humedad, destacan por la disponibilidad de calefacción central. Las tasas más altas de calefacción individual corresponden a Madrid, País Vasco y Navarra, Cataluña, Baleares, País Valenciano y Murcia. En conjunto, puede afirmarse que disponen de calefacción, cualquiera que sea su sistema, Cataluña, en el 88 por 100 de sus hogares; Madrid, 
en el 83; Navarra, en el 74; Murcia y el País Valenciano, en el 64; el País Vasco, Baleares y Aragón, en el 57; alrededor del 40 por 100 en ambas Castillas y Asturias; el 30 en Andalucía, y el 26 en Galicia; Extremadura y Canarias presentan los valores mínimos.

Entre los aparatos electrodomésticos del hogar está muy generalizado el uso del frigorífico, que poseen el 73,7 por 100 de los hogares. Cataluña, Baleares y Madrid lo poseen en proporciones superiores al 90 por 100, y junto a ellas, con valores superiores al promedio nacional, figuran Navarra y el País Vasco y Aragón, País Valenciano y Murcia. Tan sólo el 27,9 por 100 de los hogares poseen lavadora automática; Madrid y el País Vasco superan apreciablemente este nivel, seguidas de Navarra, Cataluña y Asturias, y aunque con tasa inferior, se acercan al promedio nacional Aragón y el País Valenciano. La posesión de lavavajillas afecta solamente al 2,6 por 100 de los hogares, y principalmente a Madrid, País Vasco, Navarra, Cataluña, Aragón y el País Valenciano. La aspiradora se posee en el 8,7 por 100 de los hogares, y sobresalen por sus altas tasas el País Vasco y Madrid, seguidas de Asturias, Cataluña, Baleares y Navarra.

El aparato receptor de televisión es de uso generalizado también en los hogares españoles, ya que lo poseen el 79,4 por 100 de ellos, con una dispersión reducida, ya que sólo Extremadura y Galicia presentan tasas bajas. Sobresalen por sus mayores porcentajes Madrid, el País Vasco y Navarra, Cataluña, el País Valenciano y Murcia, y se acercan al promedio nacional Aragón y Baleares, Andalucía y Asturias.

La posesión de instrumentos musicales es más reducida en los hogares españoles. Como promedio disponen de tocadiscos el 19,1 por 100, y de magnetófono el 16,3 por 100 de ellos. Sobresalen respecto al tocadiscos Madrid, Cataluña y el País Vasco, y en cuanto al magnetófono, además de las citadas, Navarra, Aragón y el País Valenciano.

Bastante similar es la distribución de las Autonomías cuyos hogares disponen de cámara fotográfica y proyector y tomavistas. En el conjunto nacional poseen la primera el 19,9 por 100 de los hogares, y de los segundos tan sólo el 3 por 100 . En cuanto a la disponibilidad de cámara fotográfica, destacan Madrid, Cataluña y el País Vasco, seguidas del País Valenciano, Baleares y Navarra; y respecto a los segundos sobresalen las mismas Autonomías, con la exclusión de Navarra y la inclusión de Canarias. 
En resumen, destacan por la mayor riqueza de su equipamiento familiar Madrid, Cataluña, País Vasco y Navarra, el País Valenciano y parcialmente Aragón y Baleares, Asturias y Murcia.

Los datos que han servido de base a este comentario corresponden a 1975, por lo que es lógico que en este último quinquenio haya mejorado sensiblemente el equipamiento familiar de España.

\section{LOS INDICADORES SOCIOECONOMICOS}

En el estudio que comentamos se incluyen informaciones elaboradas muy significativas, referentes a la realidad socioeconómica, que pueden considerarse como valiosos indicadores, a nivel de las Autonomías, para fijar la importancia relativa de cada una, con referencia a cada uno de los indicadores considerados.

A base de la amplia información presentada en el citado estudio se han reelaborado los indicadores relativos a los consumos de cemento y productos energéticos, teléfonos en servicio, recaudación por los impuestos de espectáculos y de consumo de lujo, instrumentos notariales autorizados $\mathrm{y}$, finalmente, los índices de capacidad de compra, las cuotas de riqueza activa y los niveles de desarrollo, cuyas cifras, preferentemente referidas al uso, consumo o pago por habitante, se insertan en las tablas siguientes:

\section{1." CONSUMOS ENERGETICOS Y DE CEMENTO POR HABITANTE} EN 1978

\begin{tabular}{|c|c|c|c|c|c|c|}
\hline & $\begin{array}{c}\text { Cemento } \\
\overline{\mathrm{Kgs}} \\
(1977)\end{array}$ & Carbón & $\begin{array}{l}\text { Electri- } \\
\text { cidad }\end{array}$ & $\begin{array}{c}\text { Combus- } \\
\text { tibles y } \\
\text { carbu- } \\
\text { rantes } \\
\text { líquidos }\end{array}$ & $\begin{array}{c}\text { Gases } \\
\text { licuados }\end{array}$ & $\begin{array}{c}\text { Gas } \\
\text { ciudad }\end{array}$ \\
\hline Andalucía $\ldots \ldots \ldots \ldots$ & 514 & 0,08 & 0,18 & 1,30 & 0,09 & 0,004 \\
\hline Aragón $\ldots \ldots \ldots \ldots \ldots$ & 769 & 0,86 & 0,42 & 1,32 & 0,10 & 0,004 \\
\hline $\begin{array}{lllll}\text { Asturias } & \ldots & \ldots & \ldots & \ldots\end{array}$ & 373 & 9,48 & 0,66 & 1,79 & 0,10 & 0,007 \\
\hline $\begin{array}{ccccc}\text { Baleares } & \ldots & \ldots & \ldots & \ldots\end{array}$ & 528 & 0,05 & 0,20 & 1,97 & 0,14 & 0,030 \\
\hline $\begin{array}{lllll}\text { Canarias } & \ldots & \ldots & \ldots & \ldots\end{array}$ & 669 & - & 0,10 & s. d. & s. d. & s. d. \\
\hline Castilla-La Mancha .. & 718 & 0,29 & 0,23 & 1,89 & 0,10 & - \\
\hline Castilla y León ... .. & 621 & 1,20 & 0,30 & 1,52 & 0,11 & 0,002 \\
\hline $\begin{array}{ccccc}\text { Cataluña } & \ldots & \ldots & \ldots & \ldots\end{array}$ & 597 & 0,07 & 0,33 & 1,56 & 0,12 & 0,033 \\
\hline 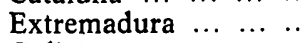 & 414 & - & 0,08 & 0,47 & 0,08 & - \\
\hline Galicia ... ............ & 597 & 0,97 & 0,22 & 1,04 & 0,09 & - \\
\hline Madrid $\ldots \ldots \ldots \ldots$ & 570 & 0,04 & 0,23 & 0,89 & 0,11 & 0,041 \\
\hline 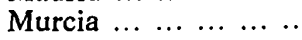 & 639 & 0,02 & 0,24 & 2,15 & 0,09 & 0,004 \\
\hline $\begin{array}{lllll} & \text { Navarra } & \ldots & \ldots & \ldots\end{array}$ & 742 & 0,02 & 0,40 & 1,71 & 0,16 & - \\
\hline País Valenciano ... .. & 694 & 0,20 & 0,24 & 1,60 & 0,12 & 0,006 \\
\hline País Vasco... ... ... .. & 591 & 0,98 & 0,57 & 2,09 & 0,14 & 0,008 \\
\hline
\end{tabular}


El consumo de cemento, cifrado en 21,7 millones de toneladas, con un valor de 594 kilogramos por habitante, se halla muy generalizado, ya que nueve Autonomías superan este consumo unitario, cubriendo una extensa zona, que comprende Galicia, ambas Castillas, Aragón y Navarra, Cataluña, País Valenciano, Murcia y Canarias. El mayor consumo corresponde a Aragón y Navarra, y el más bajo a Asturias y Extremadura.

En cuanto al consumo de productos energéticos, expresado en unidades Tec, es de resaltar, en primer término, el del carbón, cifrado en 22,7 millones de unidades Tec, con un consumo por habitante de 0,61 unidades Tec, valor sólo superado por cinco Autonomías: Galicia, Asturias, Castilla y León, País Vasco y Aragón, sobresaliendo por su elevado consumo Asturias, que es, a la vez, la principal zona productora, y, a menor nivel, la de su limítrofe, Castilla y León.

El consumo de energía eléctrica se cifra en 10,1 millones de unidades Tec, con un consumo por habitante de 0,27 unidades Tec. En líneas generales, la zona de máximos consumos de energía eléctrica, superiores al promedio nacional, coincide con la del consumo de carbón, ya que comprende, como aquélla, a Asturias, Castilla y León, País Vasco y Aragón, si bien no debe contarse con Galicia y debe añadirse a Navarra y a Cataluña. Las tasas más elevadas de consumo corresponden a Asturias y al País Vasco.

El consumo de combustibles y carburantes líquidos alcanza a 50,6 millones de unidades Tec, con un consumo por habitante de 1,37 unidades Tec, y se extiende principalmente a una zona con valores máximos, que comprende: Asturias, ambas Castillas, País Vasco y Navarra, País Valenciano, Murcia y Baleares. Las más altas tasas de consumo corresponden a Murcia y al País Vasco.

El consumo de gases licuados está más generalizado, al igual que el de los combustibles y carburantes líquidos, entre las Autonomías, y por ello la dispersión de sus valores es menor que la correspondiente a los del carbón y la energía eléctrica. Alcanza a 3,9 millones de unidades Tec, con un valor por habitante de 0,10 unidades Tec. Tan sólo Galicia, Extremadura, Andalucía y Murcia registran niveles de consumo inferiores al nacional.

Por el contrario, el consumo de gas ciudad, tan sólo medio millón de unidades Tec, con un consumo por habitante de 0,013, sólo tiene importancia en Madrid, Cataluña y Baleares. 
2. TELEFONOS, IMPUESTOS E INSTRUMENTOS NOTARIALES, ANO 1977

\begin{tabular}{|c|c|c|c|c|}
\hline & \multirow{2}{*}{$\begin{array}{l}\text { Teléfonos } \\
\text { en servicio }\end{array}$} & \multirow{2}{*}{$\begin{array}{l}\text { Instrumentos } \\
\text { notariales } \\
\text { autorizados }\end{array}$} & \multicolumn{2}{|c|}{$\begin{array}{l}\text { RECAUDACION } \\
\text { DE IMPUESTOS DE }\end{array}$} \\
\hline & & & Espectáculos & $\begin{array}{l}\text { Consumo } \\
\text { de lujo }\end{array}$ \\
\hline . & \multicolumn{2}{|c|}{ Por 100 habitantes } & \multicolumn{2}{|c|}{ Pesetas por habitante } \\
\hline $\begin{array}{lllll}\text { Andalucía } & \ldots & \ldots & \ldots & \ldots\end{array}$ & 16,3 & 18,92 & 30 & 1.998 \\
\hline $\begin{array}{lllllll}\text { Aragón } & \ldots & \ldots & \ldots & \ldots & \ldots\end{array}$ & 25,2 & 12,92 & 43 & 2.238 \\
\hline $\begin{array}{llllll}\text { Asturias } & \ldots & \ldots & \ldots & \ldots & \ldots\end{array}$ & 21,5 & 12,51 & 33 & 2.111 \\
\hline 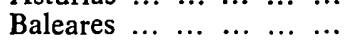 & 42,3 & 30,39 & 50 & 2.631 \\
\hline 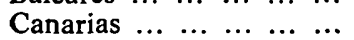 & 22,4 & 21,67 & 27 & s. d. \\
\hline Castilla-La Mancha... .... & 13,0 & 11,96 & 21 & 1.882 \\
\hline Castilla y León ... ... .... & 18,4 & 11,45 & 38 & 2.333 \\
\hline $\begin{array}{lllll}\text { Cataluña... } & \ldots & \ldots & \ldots & \ldots\end{array}$ & 36,7 & 24,20 & 55 & 5.333 \\
\hline Extremadura... $\ldots \ldots \ldots$ & 11,0 & 10,53 & 17 & 1.134 \\
\hline $\begin{array}{llllll}\text { Galicia } & \ldots & \ldots & \ldots & \ldots & \ldots\end{array}$ & 14,0 & 10,38 & 15 & 1.781 \\
\hline $\begin{array}{llllll}\text { Madrid } \ldots & \ldots & \ldots & \ldots & \ldots\end{array}$ & 47,1 & 26,44 & 67 & 4.220 \\
\hline $\begin{array}{cccccc}\text { Murcia } & \ldots & \ldots & \ldots & \ldots & \ldots\end{array}$ & 16,9 & 18,28 & 32 & 1.951 \\
\hline $\begin{array}{cccccc}\text { Navarra } & \ldots & \ldots & \ldots & \ldots & \ldots\end{array}$ & 25,4 & 14,58 & 47 & 1.207 \\
\hline País Valenciano... ... ... & 24,5 & 21,87 & 40 & 2.711 \\
\hline País Vasco $\ldots . . . . . . . .$. & 33,0 & 17,62 & 57 & 3.269 \\
\hline
\end{tabular}

Los teléfonos en servicio, considerados como exponente del grado de actividad económica, constituyen un indicador muy influido por la concentración de la población. Existe una gran desigualdad entre las Autonomías respecto a la dotación de servicio telefónico. Cifrados en 9,5 millones los teléfonos en servicio, lo que equivale a 26 teléfonos por cada 100 habitantes, se concentran en Madrid, Baleares, Cataluña y el País Vasco, únicas Autonomías que superan el promedio nacional, al que, si bien, se aproximan Aragón, Navarra y el País Valenciano. Los valores mínimos corresponden a Extremadura, Castilla-La Mancha y Galicia.

El número de instrumentos notariales autorizados, 6,9 millones en 1977 , con un promedio de 18,83 por 100 habitantes, presenta una concentración de valores máximos en Baleares, Madrid, Cataluña, País Valenciano, Canarias y Andalucía.

La recaudación de impuestos por espectáculos, también indicador del nivel económico, se elevó en 1977 a 1.493,3 millones de pesetas, con un valor promedio de 41 pesetas por habitante. Se ratifica la concentración de valores superiores al promedio nacional en Madrid, País Vasco, Cataluña, Baleares, Navarra y Aragón; y lo propio ocurre con la recaudación del impuesto de consumo de lujo, con un valor de $104.484,9$ millones de pesetas, que representa un promedio de 2.859 pesetas por habitante, y cuyos valores más elevados se limitan aún más a sólo Cataluña, Madrid y el País Vasco. 
3. INDICES DE CAPACIDAD DE COMPRA, CUOTAS DE RIQUEZA ACTIVA Y NIVELES DE DESARROLLO, EN 1978

\begin{tabular}{|c|c|c|c|c|c|}
\hline & \multicolumn{3}{|c|}{$\begin{array}{c}\text { INDICES DE CAPACIDAD } \\
\text { DE COMPRA }\end{array}$} & \multirow{2}{*}{$\begin{array}{l}\text { Cuotas } \\
\text { de riqueza } \\
\text { activa }\end{array}$} & \multirow{2}{*}{$\begin{array}{l}\text { Nivel de ce cesrollo } \\
\text { dearre }\end{array}$} \\
\hline & $1 .^{\circ}$ & $2 .^{\circ}$ & $3 .^{\circ}$ & & \\
\hline $\begin{array}{lllllll}\text { Andalucía } & \ldots & \ldots & \ldots & \ldots & \ldots\end{array}$ & 0,83 & 0,76 & 0,74 & $14.344,9$ & 85,5 \\
\hline $\begin{array}{lllllllllll}\text { Aragón } & \ldots & \ldots & \ldots & \ldots & \ldots & \ldots\end{array}$ & 0,94 & 0,97 & 0,97 & $3.322,4$ & 103,8 \\
\hline $\begin{array}{llllll}\text { Asturias } & \ldots & \ldots & \ldots & \ldots & \ldots\end{array}$ & 0,83 & 0,81 & 0,81 & $2.838,5$ & 93,3 \\
\hline Baleares $\ldots \ldots \ldots \ldots \ldots$ & 2,02 & 1,83 & 1,63 & $1.984,0$ & 109,0 \\
\hline $\begin{array}{llllll}\text { Canarias } & \ldots & \ldots & \ldots & \ldots & \ldots\end{array}$ & 0,83 & 0,76 & 0,71 & $3.558,1$ & 86,6 \\
\hline Castilla-La Mancha ... ... & 0,71 & 0,68 & 0,69 & $3.578,3$ & 82,5 \\
\hline Castilla y León ... & 0,87 & 0,86 & 0,86 & $8.370,2$ & 95,6 \\
\hline $\begin{array}{llllll}\text { Cataluña } & \ldots & \ldots & \ldots & \ldots & \ldots\end{array}$ & 1,26 & 1,34 & 1,38 & $19.658,6$ & 122,3 \\
\hline $\begin{array}{lllll}\text { Extremadura } & \ldots & \ldots & \ldots & \ldots\end{array}$ & 0,63 & 0,56 & 0,54 & $2.166,6$ & 78,0 \\
\hline $\begin{array}{ccccccc}\text { Galicia } & \ldots & \ldots & \ldots & \ldots & \ldots & \ldots\end{array}$ & 0,71 & 0,68 & 0,69 & $5.344,4$ & 72,3 \\
\hline 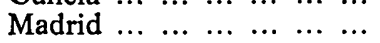 & 1,31 & 1,39 & 1,41 & $14.946,0$ & 121,2 \\
\hline $\begin{array}{ccccccc}\operatorname{Murcia} & \ldots & \ldots & \ldots & \ldots & \ldots & \ldots\end{array}$ & 0,84 & 0,78 & 0,78 & $2.064,4$ & 83,9 \\
\hline 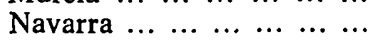 & 0,97 & 0,98 & 0,96 & $1.370,8$ & 102,9 \\
\hline País Valenciano $\ldots \ldots . . . .$. & 1,03 & 1,04 & 1,03 & $9.895,8$ & 102,0 \\
\hline País Vasco... $\ldots \ldots \ldots \ldots$ & 1,07 & 1,11 & 1,12 & $6.557,0$ & 111,6 \\
\hline
\end{tabular}

De los indices de capacidad de compra, el primero se refiere a productos de uso y consumo común, de bajo precio unitario; el segundo a artículos de tipo medio no fuertemente especializados, cuyo uso o consumo no está en función del volumen de población, y el tercero a productos de uso y consumo especializado. En los tres índices la distribución por Autonomías aparece muy similar. En los tres destacan Madrid, Cataluña, Baleares, el País Vasco y el País Valenciano.

En la distribución por cuotas de riqueza activa, calculadas sobre la base de los índices demográfico, cultural y económico, con arreglo a la metodología tradicionalmente aplicada por el equipo autor del trabajo que comentamos, se ratifica una vez más la tendencia de esta distribución autonómica de los indicadores que hemos examinado con anterioridad. Las cuotas más altas son las correspondientes a Cataluña, Madrid, Andalucía, País Valenciano, Castilla y León y el País Vasco.

Esta distribución puede resultar parcialmente corregida si tenemos en cuenta los niveles de desarrollo, que no son otra cosa que las cuotas de riqueza activa "per capita». De su examen se deduce que con valores superiores al nacional se sitúan siete Autonomías, que, en orden de cuantía, son: Cataluña, Madrid, País Vasco, Baleares, Aragón, Navarra y el País Valenciano, que podemos considerar como el resumen y expresión última del presente comentario. 


\section{REVISTA}

DE

\begin{tabular}{l} 
DE \\
ESTUDIOS \\
DE LAA \\
DIIACAL LOCAL \\
\hline
\end{tabular}

\section{JURISPRUDENCIA}


REVL-1980, núm. 208. BALLESTER ROS, IGNACIO. NOTAS SOBRE EL MARCO SOCIOECONOMICO... REVL-1980, núm. 208. BALLESTER ROS, IGNACIO. NOTAS SOBRE EL MARCO SOCIOECONOMICO... 